\title{
PENGEMBANGAN MEDIA PEMBELAJARAN MENGGUNAKAN ADOBE FLASH CS6 PADA MATERI BARISAN DAN DERET ARITMETIKA
}

\author{
Anisa Fitriyani ${ }^{1}$, H. Fuad Nasir, Drs., M.Si ${ }^{2}$, Setiyani, M.Pd ${ }^{3}$ \\ Universitas Swadaya Gunung Jati ${ }^{1,2,3}$ \\ anisafitriyani997@gmail.com
}

\begin{abstract}
Abstrak
Penelitian ini bertujuan untuk mengetahui nilai kevalidan suatu media pembelajaran menggunakan Adobe Flash CS6 pada materi barisan dan deret aritmetika yang telah dikembangkan. Mengingat masa sekarang ini sulit untuk melakukan pembelajaran secara tatap muka maka guru harus kreatif membuat media pembelajaran yang menarik. Penelitian ini merupakan penelitian kualitatif dengan menggunakan model ADDIE yang terbatas hanya sampai tahapan development. Instrumen yang digunakan berupa lembar validasi ahli. Analisis data dilakukan dengan analisis data deskriptif. Hasil penelitian menunjukan bahwa media pembelajaran yang telah dirancang dengan menggunakan Adobe Flash CS6 pada materi barisan dan deret aritmetika memperoleh persentase sebesar $97,125 \%$ berdasarkan hasil validasi ahli yang telah dianalisis. Berdasarkan hasil tersebut maka dapat dikatakan bahwa media pembelajaran menggunakan Adobe Flash CS6 ini merupakan media yang sangat efektif untuk membantu proses pembelajaran agar pembelajaran yang dilakukan tidak membosankan dan siswa menjadi lebih tertarik.
\end{abstract}

Kata Kunci: Adobe Flash CS6, Barisan dan Deret Aritmatika.

\begin{abstract}
This study aims to determine the value of validity, using learning media Adobe Flash CS6 on the developed arithmetic sequence and series material. Given that nowadays it is difficult to do face-to-face learning, thunder must be creative in making interesting learning media. This research is a qualitative study using the ADDIE model which is limited only to the development stage. The instrument used was an expert validation sheet. Data analysis was performed by descriptive data analysis. The results showed that the learning media that had been designed using Adobe Flash CS6 on the arithmetic sequence and series material obtained a proportion of $97.125 \%$ based on the results of expert validation that had been analyzed. Based on these results, it can be said that the learning media using Adobe Flash CS6 are a very effective medium to help the learning process so that learning is not boring and students become more interested.
\end{abstract}

Keywords: Adobe Flash CS6, Learning Media. 


\section{PENDAHULUAN}

Masa pandemi ini banyak faktor yang mempengaruhi proses belajar mengajar di rumah, baik dari segi siswa itu sendiri maupun dari faktor-faktor lain seperti fasilitas, serta media pendidik. Proses pembelajaran perlu dirancang dan dilaksanakan sedemikian rupa, termasuk penggunaan teknologi. Teknologi memiliki peran penting terhadap pembelajaran. Peran guru dalam pembelajaran tidak dapat digantikan oleh teknologi. Dan dengan adanya teknologi maka potensi guru akan semakin dikuatkan melalui digitalisasi pendidikan. Maka itu, teknologi menjadi alat untuk mengoptimalisasi layanan, meningkatkan kualitas interaksi akademik siswa dengan mengintegrasikan kecanggihan teknologi.

Perkembangan pesat dalam bidang teknologi digital mendorong adanya inovasi bidang pendidikan yang memanfaatkan kemajuan tersebut. Salah satunya adalah Adobe Flash CS6 yang sudah banyak digunakan untuk media pembelajaran dalam berbagai disiplin ilmu termasuk matematika. Beberapa hasil penelitian terkait Adobe Flash CS6 sebagai media pembelajaran. Hidayatullah [1] menyebutkan bahwa Adobe Flash CS6 dapat digunakan lebih mudah dalam membuat media berbasis mikroprosesor. Hal ini dikarenakan Adobe Flash CS6 memiliki tampilan, fungsi dan pilihan palet yang beragam, serta kumpulan tools yang sangat lengkap. Adobe Flash CS6 sebagai media pembelajaran sudah sering digunakan oleh berbagai disiplin ilmu namun untuk matematika Adobe Flash CS6 sebagai media pembelajaran bukan hal baru. Sudah ada beberapa peneliti yang melakukan penelitian pengembangan media pembelajaran menggunakan Adobe Flash CS6, akan tetapi hanya terdapat beberapa penelitian yang menerapkannya pada materi barisan dan deret aritmetika. Salah satu peneliti yang meneliti pengembangan media pembelajaran menggunakan Adobe Flash CS6 pada materi barisan dan deret aritmatika yaitu Sindy [2] melakukan penelitian media pembelajaran Adobe Flash CS6 dengan hasil analisis rata-rata validasi media pembelajaran yaitu sebesar $92,15 \%$ yang termasuk ke dalam kategori sangat valid, sedangkan hasil analisis rata-rata kepraktisan media pembelajaran yaitu sebesar 92,66\% yang termasuk ke dalam kategori sangat praktis. Hal ini juga didukung oleh beberapa peneliti, antara lain: Yuhdi [3] pembelajaran lebih mudah dimengerti. Benidictus [4] siswa lebih mudah mengkonstruksi pemahaman yang lebih baik tentang teorema Pythagoras.

Berdasarkan hasil penelitian dan pengembangan media pembelajaran matematika berbasis multimedia interaktif menggunakan Adobe Flash CS6 pada materi barisan dan deret aritmatika kelas XI SMA dapat disimpulkan bahwa telah dihasilkan media pembelajaran yang teruji kelayakannya berupa media yang sudah valid dan praktis.

Oleh karena itu perlu adanya beberapa peneliti untuk meneliti pengembangan media pembelajaran menggunakan Adobe Flash CS6 pada materi barisan dan deret aritmetika sehingga dapat diketahui bahwa media pembelajaran menggunakan Adobe Flash CS6 memang valid untuk materi barisan dan deret aritmetika. Terutama pada jenjang SMA sehingga semakin valid penggunaan Adobe Flash CS6 sebagai media pembelajaran materi barisan dan deret aritmetika pada siswa SMA. 


\section{METODE}

Penelitian ini digolongkan pada penelitian pengembangan yang berfokus menghasilkan suatu media pembelajaran yang dapat membantu siswa dalam memahami materi barisan dan deret aritmetika. Penelitian pengembangan ini dimodifikasi menurut Borg dan Gall, pada penelitian ini dikembangkan suatu media pembelajaran interaktif dengan menggunakan Adobe Flash CS6 dengan materi barisan dan deret aritmetika. Desain pada penelitian pengembangan ini menggunakan model pengembangan ADDIE yang memiliki 5 tahapan yaitu: 1) Analyze (Analisis), 2) Design (Desain), 3) Develop (Pengembangan), 4) Implement (Implementasi), 5) Evaluate (Evaluasi).

Adapun tahapan model ADDIE adalah Analysis, Design, Development, Implementation, dan Evaluation. Akan dijelaskan sebagai berikut:

a. Analisis (Analysis)

Langkah analisis terdiri atas dua tahap, yaitu analisis kinerja atau performance analysis dan analisis kebutuhan atau need analysis. Tahap pertama, yaitu analisis kinerja dilakukan untuk mengetahui dan mengklarifikasi apakah masalah kinerja perlu dilakukan solusi berupa penyelenggaraan program pembelajaran atau perbaikan manajemen. Tahap kedua, yaitu analisis kebutuhan merupakan langkah yang diperlukan untuk menentukan kemampuan-kemampuan atau kompetensi yang perlu dipelajari oleh siswa untuk meningkatkan kinerja atas prestasi belajar. Hal ini dapat dilakukan apabila program pembelajaran dianggap sebagai solusi dari masalah pembelajaran yang sedang dihadapi. Rahman [5] pada tahap ini juga merupakan suatu proses mendefinisikan apa yang akan dipelajari oleh siswa. Oleh karena itu, output yang akan kita hasilkan adalah berupa karakteristik atau profil calon siswa, identifikasi kesenjangan, identifikasi kebutuhan, dan analisis tugas yang rinci didasarkan atas kebutuhan. Jadi pada tahap ini pendidik/pendesain sistem pembelajaran harus memperhatikan komponen-komponen penunjang agar proses belajar mengajar dapat berjalan sesuai dengan yang direncanakan. Pendesain harus mengetahui terlebih dahulu pengetahuan, karakteristik, keterampilan yang dimiliki oleh siswa serta kemampuan apa yang perlu dimiliki oleh siswa.

\section{b. Desain (Design)}

Desain adalah langkah kedua dari model sistem pembelajaran ADDIE. Pada langkah ini diperlukan adanya klarifikasi program pembelajaran yang didesain sehingga program tersebut dapat mencapai tujuan pembelajaran seperti yang diharapkan. Pada langkah desain, pusat perhatian perlu difokuskan pada upaya untuk menyelidiki masalah pembelajaran yang sedang dihadapi. Hal ini merupakan inti dari langkah analisis, yaitu mempelajari masalah dan menemukan alternatif solusi yang akan ditempuh untuk dapat mengatasi masalah pembelajaran yang 
berhasil diidentifikasi melalui langkah analisis kebutuhan. Menurut Rahman [5] langkah penting dalam desain adalah menentukan pengalaman belajar atau learning experience yang perlu dimiliki oleh siswa selama mengikuti aktivitas belajar. Langkah desain juga harus mampu menjawab pertanyaan apakah program pembelajaran yang didesain dapat digunakan untuk mengatasi kesenjangan performa (performance gap) yang terjadi pada diri siswa. Jadi pada tahap desain ini merupakan langkah lanjutan setelah analisis. Setelah masalah-masalah dianalisis maka harus dicari solusi alternatif, dengan merancang sistem pembelajaran yang sesuai sehingga tujuan pembelajaran dapat dicapai dengan baik oleh siswa. Dan untuk mengetahui apakah program pembelajaran yang didesain dapat digunakan untuk mengatasi masalahmasalah yang terjadi pada siswa atau tidak.

\section{c. Pengembangan (Development)}

Menurut Rahman [5] pengembangan merupakan langkah ketiga dalam implementasi model desain sistem pembelajaran ADDIE. Langkah pengembangan meliputi kegiatan membuat, member dan memodifikasi bahan ajar atau learning materials untuk mencapai tujuan pembelajaran yang telah ditentukan. Pengadaan bahan ajar perlu disesuaikan dengan tujuan pembelajaran spesifik atau learning outcomes yang telah dirumuskan oleh desainer atau perancang program pembelajaran dalam langkah desain. Langkah pengembangan dengan kata lain mencakup kegiatan memilih dan menentukan metode, media serta strategi pembelajaran yang sesuai untuk digunakan dalam menyampaikan materi atau substansi program pembelajaran. Jadi pada Langkah pengembangan ini merupakan penjabaran dari langkah desain, setelah pembelajaran didesain maka apa yang ada dalam desain pembelajaran dikembangkan untuk mencapai tujuan pembelajaran tersebut. Seperti mengembangkan materi pelajaran, strategi pembelajaran, pengembangan media pembelajaran dan penunjang pembelajaran lainnya.

\section{d. Implementasi (Implementation)}

Implementasi atau penyampaian materi pembelajaran merupakan langkah keempat dari model desain sistem pembelajaran ADDIE. Menurut Rahman [5] langkah implementasi sering diasosiasikan dengan penyelenggaraan program pembelajaran itu sendiri. Langkah ini memang mempunyai makna adanya penyampaian materi pembelajaran dari guru atau instruktur kepada siswa. Jadi pada tahap ini merupakan realisasi dari langkah pengembangan atau dalam kata lain ada proses penyampaian materi dan informasi. Guru membimbing siswa untuk memperoleh pengetahuan sehingga tujuan pembelajaran dapat tercapai. Pendesain juga harus memperhatikan model dan strategi pembelajaran apa yang efektif untuk digunakan dalam penyampaian materi, karena akan mempengaruhi pencapaian tujuan pembelajaran. 


\section{e. Evaluasi (Evaluation)}

Langkah terakhir atau kelima dari model desain pembelajaran ADDIE adalah evaluasi. Evaluasi dapat didefinisikan sebagai sebuah proses yang dilakukan untuk memberikan nilai terhadap program pembelajaran. Pada dasarnya, evaluasi dapat dilakukan sepanjang pelaksanaan kelima langkah model ADDIE. Pada langkah analisis misalnya, proses evaluasi dilaksanakan dengan cara mengklarifikasi terhadap kompetensi pengetahuan, keterampilan, dan sikap yang harus dimiliki oleh siswa setelah mengikuti program pembelajaran. Evaluasi ini dikenal dengan istilah evaluasi formatif. Disamping itu, evaluasi juga dapat dilakukan dengan cara membandingkan antara hasil pembelajaran yang telah dicapai oleh siswa dengan tujuan pembelajaran yang telah dirumuskan sebelumnya. Evaluasi ini merupakan proses yang dilakukan untuk memberikan nilai terhadap program pembelajaran. Penilaian terhadap kompetensi, pengetahuan, keterampilan, sikap siswa setelah memperoleh program pembelajaran tersebut. Evaluasi ini merupakan tahap akhir dari proses pembelajaran.

Teknik pengumpulan data yang digunakan pada penelitian ini berupa lembar wawancara serta lembar validasi. Lembar wawancara digunakan sebagai teknik pengumpulan data yang dilakukan peneliti untuk menemukan permasalahan yang harus diteliti. Hal spesifik yang dimaksudkan adalah mengenai media pembelajaran yang digunakan oleh guru dan siswa selama pembelajaran, khususnya pada kelas XI semester ganjil. Selanjutnya lembar validasi digunakan untuk memperoleh penilaian kevalidan dari tim ahli mengenai media yang telah dikembangkan.

Penelitian ini menggunakan analisis data deskriptif dengan satu variabel yaitu kualitas media pembelajaran berdasarkan materi barisan dan deret aritmetika yang telah termuat dalam beberapa referensi. Penyimpulan kelayakan media diidentifikasikan dengan nilai persentase skor. Semakin tinggi persentase skor pada analisis data, maka semakin tinggi pula tingkat kelayakan media pembelajaran matematika berbasis Adobe Flash CS6.

\section{HASIL DAN PEMBAHASAN}

Menurut hasil wawancara dengan salah satu guru matematika MA Negeri 3 Cirebon dalam kegiatan belajar mengajar di kelas, guru belum menggunakan media pembelajaran. Guru menggunakan buku pelajaran yang digunakan sebagai sumber untuk dijelaskan kembali kepada siswa. Sedangkan siswa, menggunakan buku yang tersedia di perpustakaan sekolah. Dalam kegiatan pembelajaran, guru kurang memanfaatkan fasilitas untuk digunakan sebagai media pembelajaran. Guru lebih sering menggunakan metode yang berada pada Kurikulum 2013 yaitu pembelajaran berpusat pada siswa, dan diselingi dengan metode ceramah. Selanjutnya ditanyakan ketersediaan fasilitas pendukung pembelajaran di lingkungan sekolah tersebut diketahui di dalam kelas tidak terdapat proyektor, 
jika ingin menggunakan proyektor harus meminjam dari Ruang Tata Usaha. Jadi permasalahan yang terdapat di sekolah tersebut yaitu penggunaan media pembelajaran yang belum efisien dan efektif. Sedangkan, sarana dan prasarana di sekolah tersebut sudah cukup memadai. Akan tetapi, proyektor tidak disediakan untuk setiap kelas.

Oleh karena itu perlu dikembangkannya media pembelajaran untuk menunjang kegiatan pembelajaran berbasis teknologi agar dapat mempermudah pembelajaran dan membantu tercapainya tujuan pembelajaran. Media pembelajaran yang dikembangkan merupakan media yang dapat membuat siswa aktif dan tidak merasa bosan dalam proses pembelajaran yang berlangsung yaitu pengembangan media pembelajaran menggunakan Adobe Flash CS6. Media pembelajaran berbasis Adobe Flash CS6 ini berisikan tentang materi barisan dan deret aritmetika dengan penyampaian yang lebih terstruktur, jelas dan menarik.

Selanjutnya terdapat contoh soal beserta penyelesaiannya agar siswa dapat memahami setiap langkah yang harus dilakukan untuk mengerjakan soal yang diberikan. Pada media Adobe Flash CS6 diberikan latihan dan kuis interaktif untuk mengetahui kemampuan siswa dalam memahami materi barisan dan deret aritmetika. Adobe Flash CS6 dikembangkan agar siswa lebih tertarik memperhatikan dan membuat siswa aktif dalam proses belajar mengajar. Selain itu, pemilihan pengembangan media ini untuk memanfaatkan teknologi.

Media pembelajaran yang telah dikembangkan selanjutnya diuji kevalidannya menggunakan lembar validasi. Berdasarkan penilaian media yang telah dilakukan oleh para ahli menggunakan lembar validasi, didapatkan hasil penilaian yang sangat baik. Media pembelajaran menggunakan Adobe Flash CS6 pada materi barisan dan deret aritmetika ini memperoleh penilaian rata-rata persentase sebesar 97,125\% dari seluruh validator dengan kriteria "Sangat Valid". Untuk itu media pembelajaran menggunakan Adobe Flash CS6 ini dapat digunakan pada pembelajaran langsung maupun tidak langsung (daring) dan dapat dilanjutkan pada tahapan implementasi. Berikut ini merupakan hasil validasi dan penilaian yang telah dilakukan oleh seluruh validator.

Tabel 1 Hasil Persentase Validator

\begin{tabular}{l|c|l|}
\hline \multicolumn{1}{|c}{ Validator } & Persentase & Keterangan \\
\hline Validator 1 & $100 \%$ & Sangat Valid \\
\hline Validator 2 & $100 \%$ & Sangat Valid \\
\hline Validator 3 & $94 \%$ & Sangat Valid \\
\hline Validator 4 & $92 \%$ & Sangat Valid \\
\hline Rata-Rata & $97,125 \%$ & \\
\hline
\end{tabular}




\section{KESIMPULAN}

Berdasarkan hasil penelitian dan hasil pengujian hipotesis seperti yang telah diuraikan, peneliti menyimpulkan bahwa: : (1) Model pembelajaraan kooperatif tipe group investigation berbantuan media pembelajaran dipandang cocok dalam membelajarkan PLSV dan PtLSV di kelas VII pada tingkat Sekolah Menengah Pertama daripada model pembelajaran langsung berbantuan media pembelajaran. (2) Model pembelajaraan kooperatif tipe group investigation berbantuan media pembelajaran dipandang cocok dalam membelajarkan PLSV dan PtLSV di kelas VII pada tingkat Sekolah Menengah Pertama daripada model pembelajaran langsung berbantuan media pembelajaran pada kelompok peserta didik yang memiliki kemampuan awal matematika tinggi. (3) Model pembelajaraan kooperatif tipe group investigation berbantuan media pembelajaran dan model pembelajaran langsung berbantuan media pembelajaran dipandang cocok dalam membelajarkan PLSV dan PtLSV di kelas VII pada tingkat Sekolah Menengah Pertama pada kelompok peserta didik yang memiliki kemampuan awal matematika rendah. Untuk pengembangan penelitian ini selanjutnya, diharapkan ada penelitian lanjutan pada mata pelajaran lain dengan melibatkan variabel moderator lain.

\section{DAFTAR RUJUKAN}

[1] Hidayatullah, Priyatno. (2011). Animasi Pendidikan Menggunakan Flash. Bandung Informatika.

[2] Sindy, S. dan Abdurrahman. (2020). Pengembangan Media Pembelajaran Matematika Berbasis Multimedia Interaktif dengan Menggunakan Adobe Flash CS6 Professional pada Materi Barisan dan Deret Kelas XI SMA. AKSIOMATIK: Jurnal Penelitian Pendidikan dan Pembelajaran Matematika, Volume 8 No. 1 (2020).

[3] Yuhdi Munadi. (2013). Media Pembelajaran, Sebuah Pendekatan Baru. Jakarta: REFERENSI (GP Press Group).

[4] Benidictus, A.C. dan Helti, L.M. (2020). Pengembangan Media Puppy Berbasis Adobe Flash CS6 untuk Pembelajaran Teorema Pythagoras. Jurnal Cendekia: Jurnal Pendidikan Matematika. Volume 04, No. 01, Mei 2020.

[5] Rahman, Muhammad dan Amri Sofan. (2013). Strategi \& Desain Pengembangan Sistem Pembelajaran. Jakarta: Prestasi Pustakaraya 